\title{
Preparation of Carbonaceous Heavy Metal Adsorbent from Cedar Bark Using Sulfur-Impregnation
}

\author{
Takaaki Wajima
}

\begin{abstract}
A novel carbonaceous adsorbent with heavy metal removal from aqueous solution was prepared from cedar bark using sulfur impregnation. The bark was cut to $1 \mathrm{~cm}$ pieces, and then immersed in $0.01-3 \quad M \quad K_{2} S$ solution to prepare sulfur-immersed materials. The immersed-materials were heated at $100-700{ }^{\circ} \mathrm{C}$ in nitrogen gas to produce the sulfur-impregnated carbonaceous adsorbent by pyrolysis. The contents of carbon and sulfur in the adsorbent and abilities of adsorbent to remove heavy metals from aqueous solution were examined. The sulfur content in sulfur-immersed materials is higher than that in raw material by sulfur-immersion, while the carbon content in sulfur-immersed materials is almost the same as that in raw material. After pyrolysis, the product prepared from cedar bark immersed in $1 \mathrm{M} \mathrm{K}_{2} \mathrm{~S}$ solution at $400{ }^{\circ} \mathrm{C}$ indicates a maximum recovery for nickel ion, regardless of sulfur content. This product has the removal ability of the heavy metals, $\mathrm{Zn}^{2+}, \mathrm{Cu}^{2+}, \mathrm{Ni}^{2+}, \mathrm{Pb}^{2+}, \mathrm{Cd}^{2+}, \mathrm{Fe}^{3+}$ and $\mathrm{Fe}^{2+}$. The equilibrium adsorption capacity of the adsorbent for heavy metal ions fits the Langmuir isotherm better than the Freundlich isotherm, and the calculated maximum adsorption capacity is $0.30-0.74 \mathrm{mmol} / \mathrm{g}$. The order of selectivity of the adsorbent indicates $\mathrm{Pb}^{2+}>\mathrm{Fe}^{2+}>\mathrm{Cu}^{2+}>\mathrm{Zn}^{2+}>\mathrm{Cd}^{2+}>\mathrm{Ni}^{2+}>$ $\mathrm{Fe}^{3+}$. For adsorption of iron ion with the adsorbent, the adsorption for divalent $\mathrm{Fe}^{2+}$ is superior to that for trivalent $\mathrm{Fe}^{3+}$, while influence of co-existing anion species for the adsorption with sulfur-impregnated adsorbent is little.
\end{abstract}

Index Terms-Cedar bark, sulfur-impregnated adsorbent, pyrolysis, heavy metal removal, wastewater treatment.

\section{INTRODUCTION}

Japanese cedar (cryptomeria japonica), an economically important tree plantation species, is widely distributed in Japan. The wood is used for lumber and veneer, while the bark generally is of little economic value. Usually, the bark is currently a huge residue stream for wood processing industries and is either discarded in sawmills or burned.

Activated carbon can be produced from various biomass materials. With the increasing ecological and economical significance of environmental protection, the use of waste biomass as feedstock material for the production of activated carbons is attracting increasing interest [1]-[6]. Activated carbon can be prepared from many organic materials having high carbon content, like coal [7], wood [8], [9], lignite [10], coconut shells [11], [12], activated sludge [13]; and recently, many agricultural by-products, such as walnut shells [14], palm shells [15], pecan shells [16], [17], date stones [18], almond shells [19], sugar cane bagasse [20], cotton stalks

Manuscript received March 15, 2017; revised July 20, 2017.

Takaaki Wajima is with the Department of Urban Environment Systems, Graduate School of Engineering, Chiba University, Japan (e-mail: wajima@tu.chiba-u.ac.jp).
[21], physic nut [22], and rice straw [23], [24], have been used as sources for activated carbon production. However, activated carbon effectively removes organic chemicals from wastewater, but is less effective in removing metals and inorganic pollutants from aqueous solutions [25]. This is mainly due to the relatively non-polar character of activated carbon, which inhibits the attraction between charged metal species and the surface of the activated carbon (even though some functional groups may be present on the surface).

In previous studies, sulfur-impregnated adsorbents with high removal abilities for heavy metals were prepared from coal or palm shell using $\mathrm{H}_{2} \mathrm{~S}$ gas, $\mathrm{K}_{2} \mathrm{~S}$ powder, or $\mathrm{K}_{2} \mathrm{~S}$ solution [26]-[29]. According to the Pearson theory, the sulfur, as a soft base, should interact with heavy metals such as $\mathrm{Zn}^{2+}, \mathrm{Pb}^{2+}, \mathrm{Cd}^{2+}$ and $\mathrm{Ni}^{2+}$ (soft acids) rather than with oxygen (a hard base) in the activated carbon [30], [31]. From these results, it would be possible to produce a low cost heavy metal adsorbent from agricultural wastes, and could be applied to recover the metal ions from wastewater.

In this study, we attempted to prepare a carbonaceous heavy metal adsorbent from cedar bark using sulfur-impregnation, and estimate its removal ability for heavy metals from aqueous solution.

\section{MATERIALS AND METHODS}

\section{A. Raw Bark}

Raw cedar bark, which was collected from one of the company in Akita prefecture, Japan, first cut into $1 \mathrm{~cm}$ length, then washed with distilled water, and dried and stored for use. Properties of cedar bark sample are shown in Table I. All reagents used in this study were purchased from Wako Chemical Co., Japan at analytical grade.

TABLE I: PROPERTIES OF CEDAR BARK SAMPLE

\begin{tabular}{lcccccc}
\hline \hline \multirow{2}{*}{ Moisture } & \multirow{2}{*}{ Ash } & \multicolumn{4}{c}{ Volatile matter + fixed carbon } \\
& & & $\mathrm{C}$ & $\mathrm{H}$ & $\mathrm{N}$ & $\mathrm{S}$ \\
\hline Content (\%) & 11.8 & 10.5 & 42.8 & 5.5 & 0.7 & 0.7 \\
\hline \hline
\end{tabular}

\section{B. Preparation of Adsorbent}

$20 \mathrm{~g}$ of sample was immersed in $200 \mathrm{~mL}$ of $\mathrm{K}_{2} \mathrm{~S}$ solution with $0.05-3 \mathrm{mmol} / \mathrm{L}$ for $24 \mathrm{~h}$, then filtered, and dried in a drying oven overnight to obtain sulfur-immersed samples. These samples were pyrolyzed using a horizontal reactor (Fig. 1) as follows. Sulfur-immersed samples were put in a ceramic board, and installed in a transparent quartz tube of $0.45 \mathrm{~mm}$ inside diameter and $1 \mathrm{~m}$ in length. Before pyrolysis, $\mathrm{N}_{2}$ gas was injected into the tube for $30 \mathrm{~min}$ at a rate of $1.0 \mathrm{~L} / \mathrm{min}$ to replace the air in the tube. The product was heated in an 
electric furnace at $100-700{ }^{\circ} \mathrm{C}$ for $1 \mathrm{~h}$, with a continuous flow of $\mathrm{N}_{2}$ gas at a rate of $1.0 \mathrm{~L} / \mathrm{min}$. After heating, the solid was cooled to room temperature with a steady $\mathrm{N}_{2}$ gas flow $(1.0 \mathrm{~L} / \mathrm{min})$ in the tube, then washed with distilled water and dried in a drying oven overnight to obtain the sulfur-impregnated adsorbent (Product).

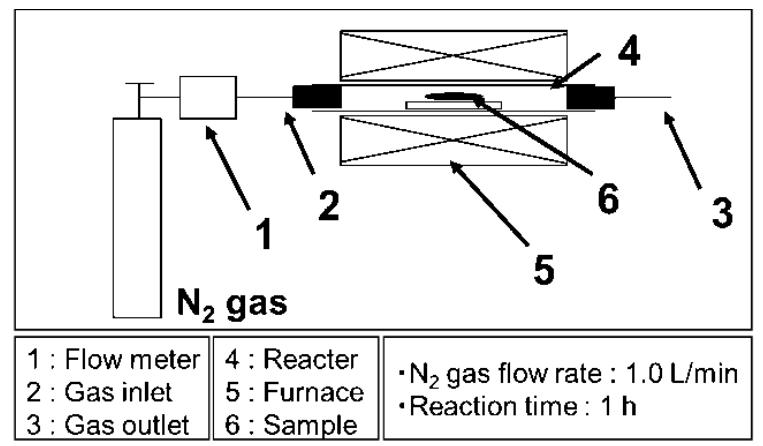

Fig. 1. Experimental apparatus.

The crystalline phases in the samples were identified using powder X-ray diffraction with monochromate $\mathrm{Cu} \mathrm{K \alpha}$ radiation (Ultima IV, Rigaku, Japan). The contents of carbon and sulfur in the sample were analyzed by $\mathrm{CHNS/O}$ elemental analysis (2400II, Perkin Elmer, Japan). The abilities of the product for recovery of nickel ion from aqueous solution were examined as follows. $0.1 \mathrm{~g}$ of the sample was added to $10 \mathrm{~mL}$ of $\mathrm{Ni}\left(\mathrm{NO}_{3}\right)_{2}$ solution with 10 $\mathrm{mM}$ in $50 \mathrm{~mL}$ centrifuged tube, and was shaken in a reciprocal shaker for $24 \mathrm{~h}$. After shaking, the slurry was centrifuged, and the $\mathrm{pH}$ of the supernatant and the concentration of $\mathrm{Ni}^{2+}$ in the supernatant were measured using a $\mathrm{pH}$ meter ( $\mathrm{pH} / \mathrm{Ion}$ meter D-53, Horiba, Japan) and inductively coupled plasma emission analyzer (SPS 5510, SII Nanotechnology Inc., Japan), respectively. The recovery ratios of $\mathrm{Ni}^{2+}$ were calculated using the following equation:

$$
R=\frac{M_{0}-M_{e}}{M_{0}} \times 100
$$

Here, $R=$ Recovery ratio of $\mathrm{Ni}^{2+}(\%), M_{0}=$ Initial concentration of $\mathrm{Ni}^{2+}$ in the solution $(\mathrm{mg} / \mathrm{L})$, and $M_{e}=$ Measure concentration of $\mathrm{Ni}^{2+}$ in the solution $(\mathrm{mg} / \mathrm{L})$.

\section{Heavy Metal Removal}

The adsorption capabilities of the products for heavy metals were examined. $0-10 \mathrm{mmol} / \mathrm{L}$ of $\mathrm{Zn}^{2+}, \mathrm{Cu}^{2+}, \mathrm{Ni}^{2+}$, $\mathrm{Pb}^{2+}, \mathrm{Cd}^{2+}, \mathrm{Fe}^{3+}$ and $\mathrm{Fe}^{2+}$ solutions were prepared with $\mathrm{Zn}\left(\mathrm{NO}_{3}\right)_{2} \cdot 6 \mathrm{H}_{2} \mathrm{O}, \mathrm{Cu}\left(\mathrm{NO}_{3}\right)_{2} \cdot 3 \mathrm{H}_{2} \mathrm{O}, \mathrm{Ni}\left(\mathrm{NO}_{3}\right)_{2} \cdot 6 \mathrm{H}_{2} \mathrm{O}$, $\mathrm{Pb}\left(\mathrm{NO}_{3}\right)_{2}, \mathrm{Cd}\left(\mathrm{NO}_{3}\right)_{2} \cdot 6 \mathrm{H}_{2} \mathrm{O}, \mathrm{Fe}\left(\mathrm{NO}_{3}\right)_{3} \cdot 9 \mathrm{H}_{2} \mathrm{O}, \mathrm{FeCl}_{3}$. $6 \mathrm{H}_{2} \mathrm{O}$ and $\mathrm{FeCl}_{2} \cdot 4 \mathrm{H}_{2} \mathrm{O}$ powders, respectively. $0.1 \mathrm{~g}$ of the product was added to $10 \mathrm{~mL}$ of heavy metal solution in a 50 $\mathrm{mL}$ centrifuge tube, and was shaken in a reciprocal shaker for 24 h. After shaking, the slurry was centrifuged, and the concentrations of heavy metal ions in the supernatant were analyzed to calculate the corresponding adsorption amounts $\left(q_{e}(\mathrm{mmol} / \mathrm{g})\right)$ :

$$
q_{e}=\frac{\left(M_{0}-M_{e}\right) \bullet V}{w}
$$

Here, $V$ is the volume of solution (L) and $w$ is the weight of sample (g).

\section{RESULTS AND DISCUSSION}

\section{A. Sulfur-impregnated Adsorbent}

Effect of pyrolysis temperature on the properties of the product was examined.

Fig. 2 shows the XRD pattern of raw cedar bark, sulfur-immersed cedar bark immersed in $1 \mathrm{~mol} / \mathrm{L} \mathrm{K}_{2} \mathrm{~S}$ solution for $24 \mathrm{~h}$, and the product pyrolyzed at $100-700{ }^{\circ} \mathrm{C}$. The peaks of cellulose were indicated in cedar bark, sulfur-immersed cedar bark and the product pyrolyzed at 100 ${ }^{\circ} \mathrm{C}$ and $200{ }^{\circ} \mathrm{C}$, while those in the product pyrolyzed above $300^{\circ} \mathrm{C}$ are decreasing to indicate broad pattern. It means that cellulose structure was decomposed at pyrolysis above 300 ${ }^{\circ} \mathrm{C}$ to form amorphous structure in the product.

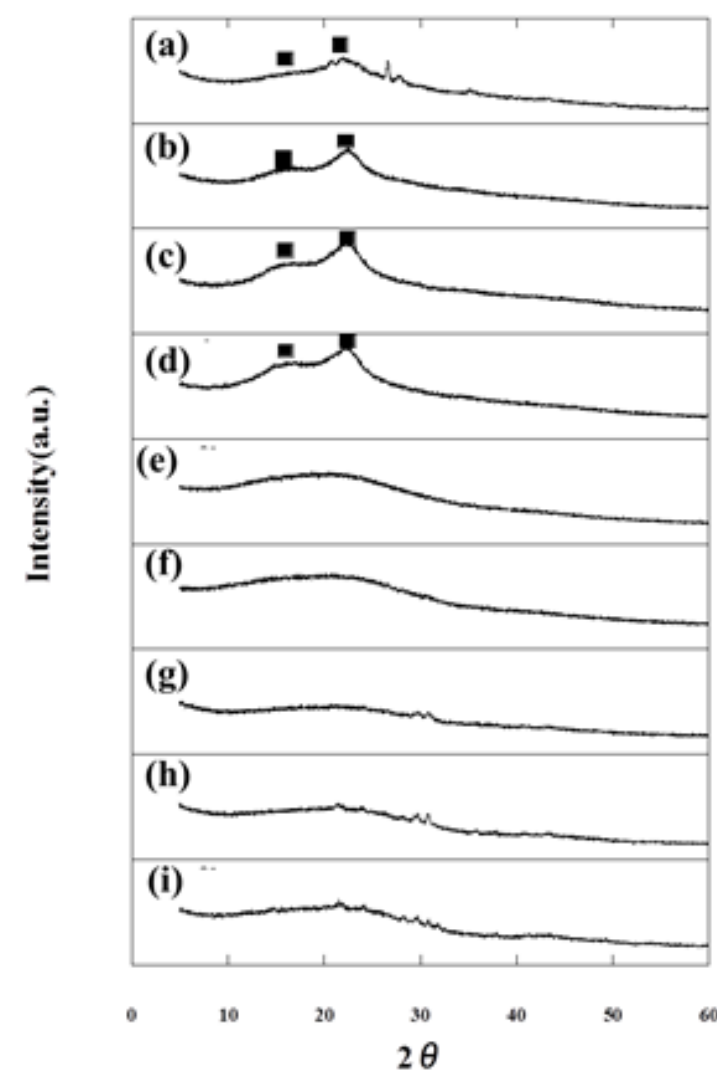

Fig. 2. XRD patterns of (a) cedar bark, (b) sulfur-immersed cedar bark, and the product pyrolyzed at (c) $100{ }^{\circ} \mathrm{C}$, (d) $200{ }^{\circ} \mathrm{C}$, (e) $300{ }^{\circ} \mathrm{C}$, (f) $400{ }^{\circ} \mathrm{C}$, (g) 500 ${ }^{\circ} \mathrm{C}$, (h) $600{ }^{\circ} \mathrm{C}$ and (i) $700{ }^{\circ} \mathrm{C}$.

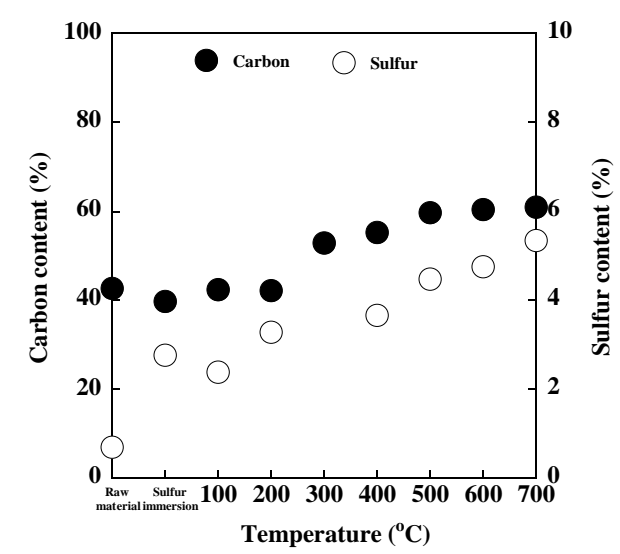

Fig. 3. Contents of carbon and sulfur in cedar bark, sulfur-immersed cedar bark, and the product pyrolyzed at $100-700{ }^{\circ} \mathrm{C}$. 
Fig. 3 shows the contents of carbon and sulfur in cedar bark, sulfur-immersed cedar bark, and the product pyrolyzed at $100-700{ }^{\circ} \mathrm{C}$. The contents of carbon and sulfur in raw cedar bark are $42.7 \%$ and $0.7 \%$, respectively. The carbon content of the samples after sulfur-immersion and pyrolysis at $100{ }^{\circ} \mathrm{C}$ and $200{ }^{\circ} \mathrm{C}$ are almost same as those of raw cedar bark, while the products pyrolyzed above $300{ }^{\circ} \mathrm{C}$ are higher contents of carbon (50 - $60 \%$ ) than raw cedar bark. The sulfur content of the sample increase after sulfur immersion (almost $3 \%$ ), and gradually increase with increasing the pyrolysis temperature above $300{ }^{\circ} \mathrm{C}$. It may be caused by the decomposition of organic matters, such as cellulose, as shown in Fig. 2, in the products by pyrolysis.

Fig. 4 shows the recovery of nickel using raw cedar bark, sulfur-immersed cedar bark, and the product pyrolyzed at $100-700{ }^{\circ} \mathrm{C}$. Nickel recovery of raw cedar bark is $7.9 \%$, that of sulfur-immersed cedar bark is $55 \%$, and the product after pyrolysis at $100{ }^{\circ} \mathrm{C}, 200{ }^{\circ} \mathrm{C}$ and $300{ }^{\circ} \mathrm{C}$ are approximately $60 \%$. With increasing temperature of pyrolysis above $300{ }^{\circ} \mathrm{C}$, nickel recovery of the products pyrolyzed at $400{ }^{\circ} \mathrm{C}$ is high (80\%), then decrease to approximately $40 \%$. The product pyrolyzed at $400{ }^{\circ} \mathrm{C}$ indicates the highest nickel recovery.

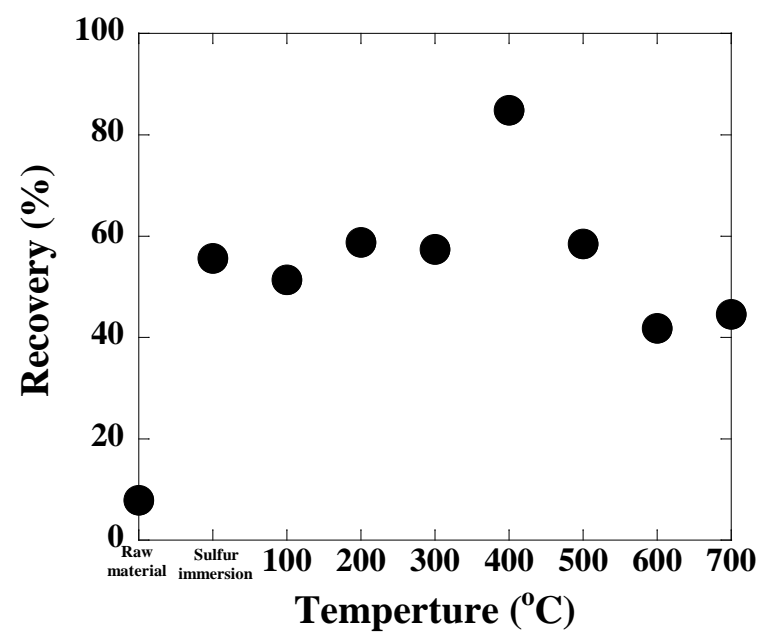

Fig. 4. Recovery of nickel ion using cedar bark, sulfur-immersed cedar bark, and the product pyrolyzed at $100-700{ }^{\circ} \mathrm{C}$.

Effect of $\mathrm{K}_{2} \mathrm{~S}$ concentration on the properties of the product was examined.

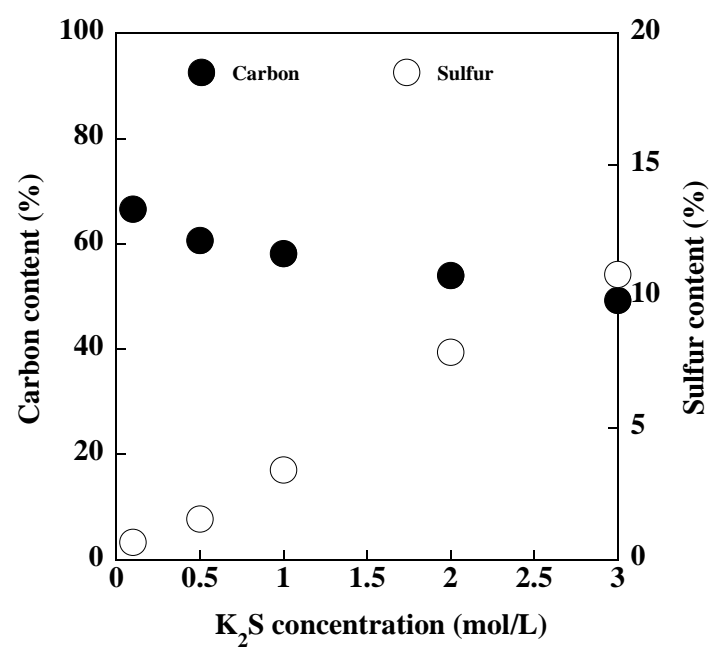

Fig. 5. Contents of carbon and sulfur in the product pyrolyzed at $400{ }^{\circ} \mathrm{C}$ from cedar bark immersed in $0-3 \mathrm{~mol} / \mathrm{L} \mathrm{K}_{2} \mathrm{~S}$ solution for $24 \mathrm{~h}$.
Fig. 5 shows the contents of carbon and sulfur in the product pyrolyzed at $400{ }^{\circ} \mathrm{C}$ from cedar bark immersed in 0 $3 \mathrm{~mol} / \mathrm{L} \mathrm{K}_{2} \mathrm{~S}$ solution for $24 \mathrm{~h}$. With increasing $\mathrm{K}_{2} \mathrm{~S}$ concentration, carbon content decreases, while sulfur content increases.

Fig. 6 shows the recovery of nickel using the product pyrolyzed at $400{ }^{\circ} \mathrm{C}$ from cedar bark immersed in $0-3 \mathrm{~mol} / \mathrm{L}$ $\mathrm{K}_{2} \mathrm{~S}$ solution for $24 \mathrm{~h}$. With increasing $\mathrm{K}_{2} \mathrm{~S}$ concentration to 1 $\mathrm{mol} / \mathrm{L}$, nickel recovery of the product increases, and above 1 $\mathrm{mol} / \mathrm{L}$, that of the product decreases.

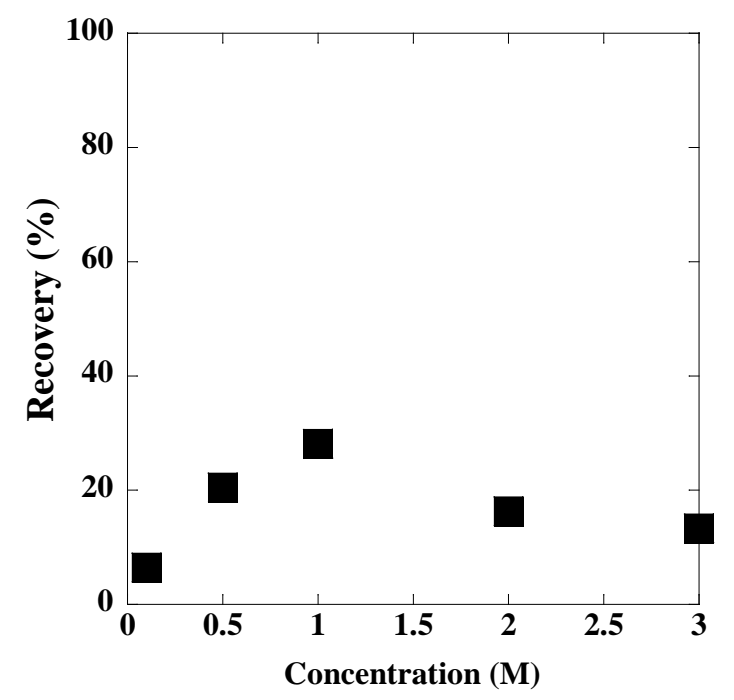

Fig. 6. Recovery of nickel ion using the product pyrolyzed at $400{ }^{\circ} \mathrm{C}$ from cedar bark immersed in $0-3 \mathrm{~mol} / \mathrm{L} \mathrm{K}_{2} \mathrm{~S}$ solution for $24 \mathrm{~h}$.

From these results, the carbonaceous adsorbent with the highest ability for nickel recovery can be prepared from cedar bark by pyrolysis at $400{ }^{\circ} \mathrm{C}$ after immersion in $1 \mathrm{M} \mathrm{K}_{2} \mathrm{~S}$ solution.

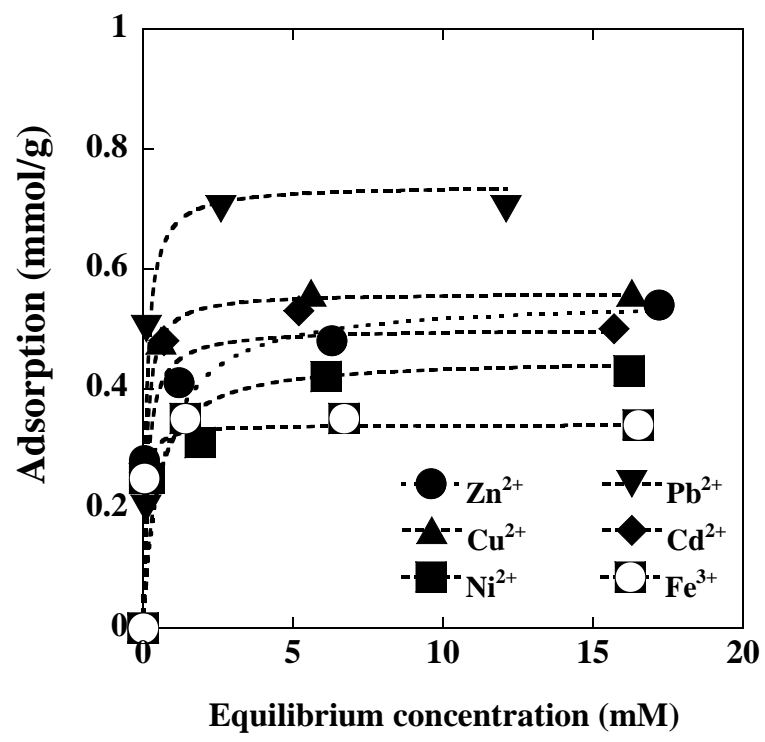

Fig. 7. Adsorption isotherms of various heavy metal ions.

\section{B. Heavy Metal Adsorption}

The adsorption isotherms of various metal ions with the adsorbent, which was prepared by pyrolysis at $400{ }^{\circ} \mathrm{C}$ after immersion in $1 \mathrm{M} \mathrm{K}_{2} \mathrm{~S}$ solution, are shown in Fig. 7 and Fig. 8. In Fig. 7, the high adsorbed amount (approx.. $0.7 \mathrm{mmol} / \mathrm{g}$ ) is confirmed for $\mathrm{Pb}^{2+}$, the adsorbed amounts for $\mathrm{Zn}^{2+}, \mathrm{Cu}^{2+}$, 
and $\mathrm{Cd}^{2+}$, are approximately $0.5 \mathrm{mmol} / \mathrm{g}$, and the low adsorbed amounts for $\mathrm{Ni}^{2+}$ and $\mathrm{Fe}^{3+}$ are about $0.4 \mathrm{mmol} / \mathrm{g}$ and $0.3 \mathrm{mmol} / \mathrm{g}$, respectively. In Fig. 8, the isotherms for three types of iron ion, $\mathrm{Fe}\left(\mathrm{NO}_{3}\right)_{3}, \mathrm{FeCl}_{3}$ and $\mathrm{FeCl}_{2}$, are compared. In the case of $\mathrm{Fe}\left(\mathrm{NO}_{3}\right)_{3}$ and $\mathrm{FeCl}_{3}$, although different co-existing anions, $\mathrm{NO}_{3}{ }^{-}$and $\mathrm{Cl}^{-}$, are present in the solution, the adsorption behaviors for $\mathrm{Fe}^{3+}$ are almost same (about 0.3 $\mathrm{mmol} / \mathrm{g}$ ). In the case of $\mathrm{FeCl}_{3}$ and $\mathrm{FeCl}_{2}$, the adsorption for divalent $\mathrm{Fe}^{2+}$ (approx. $0.6 \mathrm{mmol} / \mathrm{g}$ ) is superior to that for trivalent $\mathrm{Fe}^{3+}$.

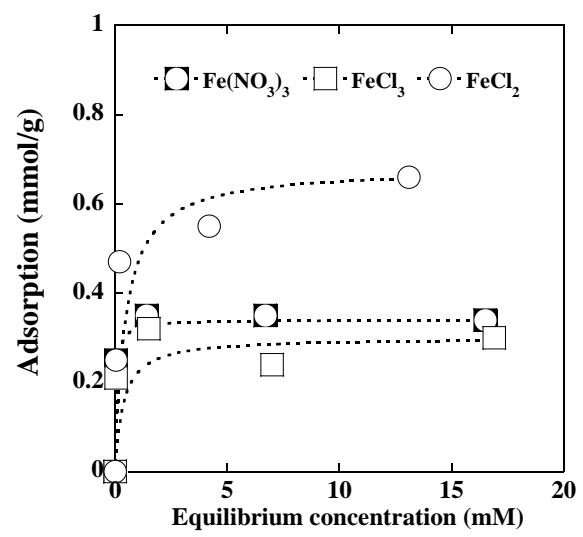

Fig. 8. Adsorption isotherms of iron ion in $\mathrm{Fe}\left(\mathrm{NO}_{3}\right)_{3}, \mathrm{FeCl}_{3}$ and $\mathrm{FeCl}_{2}$ solutions.

The adsorption behaviors of the product for metal ions are determined by the isotherm models. Several isotherm models are available to describe the equilibrium sorption distribution with the Langmuir and Freundlich models being commonly used to fit experimental data. The linear forms of the Langmuir and Freundlich models are given by:

$$
\begin{gathered}
C_{e} / q_{e}=1 /\left(Q_{\max } \bullet K_{L}\right)+C_{e} / Q_{\max } \\
\ln \left(q_{e}\right)=\ln \left(K_{F}\right)+(1 / n) \bullet \ln \left(C_{e}\right)
\end{gathered}
$$

where $q_{e}$ is the amount of metal ions adsorbed at equilibrium (mmol/g); $Q_{\max }(\mathrm{mmol} / \mathrm{g})$ and $K_{L}(\mathrm{~L} / \mathrm{mg})$ are Langmuir constants related to the maximum adsorption capacity corresponding to complete coverage of available adsorption sites and a measure of adsorption energy (equilibrium adsorption constant), respectively. $K_{F}$ and $n$ are Freundlich constants.

TABLE II: QMAX CALCULATED USING LANGMUIR MODEL FOR VARIOUS METAL IONS

\begin{tabular}{lllllll}
\hline \hline & $\mathrm{Zn}^{2+}$ & $\mathrm{Cu}^{2+}$ & $\mathrm{Ni}^{2+}$ & $\mathrm{Pb}^{2+}$ & $\mathrm{Cd}^{2+}$ & $\mathrm{Fe}^{3+}$ \\
\hline$Q_{\max }(\mathrm{mmol} / \mathrm{g})$ & 0.55 & 0.56 & 0.45 & 0.74 & 0.50 & 0.34 \\
\hline \hline
\end{tabular}

TABLE III: QMAX CALCULATED FROM LANGMUIR MODEL FOR IRON IONS

\begin{tabular}{cccc}
\hline & $\mathrm{Fe}\left(\mathrm{NO}_{3}\right)_{3}$ & $\mathrm{FeCl}_{3}$ & $\mathrm{FeCl}_{2}$ \\
\hline$Q_{\max }(\mathrm{mmol} / \mathrm{g})$ & 0.34 & 0.30 & 0.68 \\
\hline \hline
\end{tabular}

For all metal ions, the correlation regression coefficients $\left(R^{2}\right)$ of Langmuir model $\left(R^{2}=0.99-1.00\right)$ indicate a better fitting than the Freundlich model $\left(R^{2}=0.12-0.99\right)$ and the maximum adsorption capacity of the product for various metal ions calculated from Langmuir model were given in Table II and Table III. The order of selectivity of the adsorbent indicates $\mathrm{Pb}^{2+}>\mathrm{Fe}^{2+}>\mathrm{Cu}^{2+}>\mathrm{Zn}^{2+}>\mathrm{Cd}^{2+}>\mathrm{Ni}^{2+}>$ $\mathrm{Fe}^{3+}$, and the adsorbed amount for $\mathrm{Fe}^{2+}$ is twice as high as that for $\mathrm{Fe}^{3+}$.

\section{CONCLUSION}

The carbonaceous adsorbent with the removal ability for heavy metals can be prepared from cedar bark using pyrolysis followed by sulfur immerse treatment. The product prepared from cedar bark immersed in $1 \mathrm{M} \mathrm{K}_{2} \mathrm{~S}$ solution via pyrolysis at $400{ }^{\circ} \mathrm{C}$ has a maximum ability for nickel ion recovery. This product has the removal ability of the heavy metals, $\mathrm{Zn}^{2+}, \mathrm{Cu}^{2+}, \mathrm{Ni}^{2+}, \mathrm{Pb}^{2+}, \mathrm{Cd}^{2+}, \mathrm{Fe}^{3+}$ and $\mathrm{Fe}^{2+}$. The equilibrium adsorption capacity of the adsorbent for heavy metal ions fits the Langmuir isotherm better than the Freundlich isotherm, and the calculated maximum adsorption capacity is $0.30-0.74 \mathrm{mmol} / \mathrm{g}$. The order of selectivity of the adsorbent indicates $\mathrm{Pb}^{2+}>\mathrm{Fe}^{2+}>\mathrm{Cu}^{2+}>\mathrm{Zn}^{2+}>\mathrm{Cd}^{2+}>\mathrm{Ni}^{2+}>$ $\mathrm{Fe}^{3+}$. For adsorption iron ion with the adsorbent, the adsorption for divalent $\mathrm{Fe}^{2+}$ is superior to that for trivalent $\mathrm{Fe}^{3+}$, while influence of co-existing anion species for the adsorption with sulfur-impregnated adsorbent is little.

These results suggested that sulfur-impregnated adsorbent to apply for heavy metal removal from wastewater can be prepared from cedar bark.

\section{ACKNOWLEDGMENT}

This research was supported by the Environmental Research and Technology Development Fund (K113029) of the Ministry of the Environment, Japan, and JSPS KAKENHI (16K00609).

\section{REFERENCES}

[1] F. Karaosmanoglu and E. Tetik, "Charcoal from the pyrolysis of rapeseed plant straw-stalk,” Energy Sources, vol. 21, no. 6, pp. 503-510, May 1999.

[2] S. L. Wu and K. Iisa, "Kinetics of NO reduction by black liquor char," Energy \& Fuel, vol. 12, no. 3, pp. 457-463, Mar. 1998.

[3] A. Bacaoui, A. Yaacoubi, C. Bennouna, A. Dahbi, J. Ayele, and M. Mazet, "Characterisation and utilisation of a new activated carbon obtained from Moroccan olive wastes,” Aqua, vol. 47, no. 2, pp. 68-75, Apr. 1998.

[4] R. U. Edgehill and G. Q. Lu, “Adsorption characteristics of carbonized bark for phenol and pentachloriphenol,” Journal of Chemical Technology and Biotechnology, vol. 71, no. 1, pp. 27-34, Jan. 1998.

[5] N. Tancredi, T. Cordero, J. Rodriguez-Mirasol, and J. J. Rodriguez, "Activated carbons from eucalyptus wood. Influence of the carbonization temperature,” Separation Science and Technology, vol. 32, no. 6, pp. 1115-1126, Aug. 1997.

[6] C. C. Valenzuela, S. V. Gomez, A. J. Hernandez, and G. A. Bernalte, "Use of waste matter after olive grove pruning for the preparation of charcoal. The influence of the type of matter, particle size and pyrolysis temperature,” Bioresource Technology, vol. 40, no. 1, pp. 17-22, Jun. 1992.

[7] D. Cuhadaroglu and O. A. Uygun, "Production and characterization of activated carbon from a bituminous coal by chemical activation," African Journal of Biotechnology, vol. 7, no. 20, pp. 3703-3710, Oct. 2008.

[8] L. Khezamiet, A. Chetouani, B. Taouk, and R. Capart, "Production and characterization of activated carbon from wood components in powder: Cellulose, lignin, xylan,” Powder Technology, vol. 157, no. 1-3, pp. 48-56, Sep. 2005.

[9] C. Srinivasakannan and M. Z. A. Bakar, "Production of activated carbon from rubber wood sawdust,” Biomass \& Bioenergy, vol. 27, no. 1, pp. 89-96, Jul. 2004.

[10] N. Pasadakis, G. Romanos, V. Perdikatsis, and A. E. Foscolos, "The production of activated carbons using Greek lignites by physical and 
chemical activation methods: A comparative study,” Energy Sources, vol. 33, no. 8, pp. 713-723, Feb. 2011.

[11] M. Z. Hussein, R. S. H. Tarmizi, Z. Zainal, R. Ibrahim, and M. Badri, "Preparation and characterization of activated carbons from oil palm coconut shells," Carbon, vol. 34, no. 11, pp. 1447-1449, Oct. 1996.

[12] M. K. Gratuito, B. T. Panyathanmaporn, R. A. Chumnanklang, N. Sirinuntawittaya, and A. Dutta, "Production of activated carbon from coconut shell: Optimization using response surface methodology," Bioresource Technology, vol. 99, no. 11, pp. 4887-4895, Jul. 2008.

[13] Z. Al-Qodah and R. Shawabkah, "Production and characterization of granular activated carbon from activated sludge," Brazilian Journal of Chemical Engineering, vol. 26, no. 1, pp. 127-136, Jan./Mar. 2009.

[14] J. W. Kim, M. H. Sohn, D. S. Kim, S. M. Sohn, and Y. S. Kwon, "Production of granular activated carbon from waste walnut shell and its adsorption characteristics for $\mathrm{Cu}^{2+}$ ion," Journal of Hazardous Materials, vol. 85, no. 3, pp. 301-315, Aug. 2001.

[15] N. Buasri, C. Chaiyut, and C. Nakweang, "Preparing activated carbon from palm shell for biodiesel fuel production," Chiang Mai Journal of Science, vol. 38, pp. 572-578, 2011.

[16] R. R. Bansode, J. N. Losso, W. E. Marshall, R. M. Rao, and R. J. Portier," Pecan shell-based granular activated carbon for treatment of chemical oxygen demand (COD) in municipal wastewater," Bioresource Technology, vol. 94, no. 2, pp. 129-135, Sep. 2004.

[17] S. A. Dastgheib and D. A. Rockstraw, "Pecan shell activated carbon: Synthesis, characterization, and application for the removal of copper from aqueous solution," Carbon, vol. 39, no. 12, pp. 1849-1855, Oct. 2001.

[18] Y. A. S. Alhamed, "Activated carbon from Dates' Stone by $\mathrm{ZnCl}_{2}$ activation,” JKAU: Engineering Science, vol. 17, pp. 75-100, 2006.

[19] I. Bhatti, K. Qureshi, R. A. Kazi, and A. K. Ansari, "Preparation and characterisation of chemically activated almond shells by optimization of adsorption parameters for removal of chromium VI from aqueous solutions," World Academy of Science, Engineering, Technology, vol. 34, pp. 199-204, 2007.

[20] E. F. Jaguaribe, L. L. Medeiros, M. C. S. Barreto, and L. P. Araujo, "The performance of activated carbons from sugarcane bagasse, babassu, and coconut shells in removing residual chlorine," Brazilian Journal of Chemical Engineering, vol. 22, no. 1, pp. 41-47, Jan./Mar. 2005.

[21] M. El Zayat and E. Smith, "Removal of heavy metals by using activated carbon produced from cotton stalks," Canadian Journal on Environmental, Construction and Civil Engineering, vol. 1, pp. 71-79, 2010.

[22] P. Chiravoot, A. Duangdao, A. Duangduen, and S. Viboon, "Physicochemical properties of carbons prepared from physic nut waste by phosphoric acid and potassium hydroxide activations," Materials Science Forum, vol. 561-565, pp. 1719-1722, Oct. 2007.

[23] P. Gao, Z. H. Liu, G. Xue, B. Han, and M. H. Zhou, "Preparation and characterization of activated carbon produced from rice straw by
$\left(\mathrm{NH}_{4}\right)_{2} \mathrm{HPO}_{4}$ activation,” Bioresource Technology, vol. 102, no. 3, pp. 3645-3648, Feb. 2011.

[24] N. Yahaya, E. M. Pakir, M. F. Latiff, M. I. Abustan, and M. A. Ahmad, "Effect of preparation conditions of activated carbon prepared from rice husk by $\mathrm{ZnCl}_{2}$ activation for removal of $\mathrm{Cu}$ (II) from aqueous solution,” International Journal of Engineering \& Technology, vol. 10, no. 6, pp. 28-32, Dec. 2010.

[25] N. Adhoum and L. Monser, "Removal of cyanide from aqueous solution using impregnated activated carbon," Chemical Engineering and Processing, vol. 41, no. 1, pp. 17-21, Jan. 2002.

[26] K. Sugawara, T. Wajima, T. Kato, and T. Sugawara, "Preparation of carbonaceous heavy metal adsorbent from palm shell using sulfur impregnation,” Ars Separatoria Acta, vol. 5, pp. 88-98, 2007.

[27] T. Wajima, K. Murakami, and K. Sugawara, "Preparation of carbonaceous heavy metal adsorbent from coal using sulfur impregnation,” Energy Sources A., vol. 32, no. 5, pp. 442-449, Dec. 2009.

[28] T. Wajima and K. Sugawara, "Adsorption behaviors of mercury from aqueous solution using sulfur-impregnated adsorbent developed from coal,” Fuel Processing Technology, vol. 92, no. 7, pp. 1322-1327, Jul. 2011.

[29] T. Wajima, "Preparation of carbonaceous heavy metal adsorbent from paper sludge using sulfur impregnation," in Proc. 28th International Conference on Solid Waste Technology and Management (ICSW2013), 2013, pp. 630-638.

[30] R. G. Pearson, "Hard and soft acids and bases," Journal of American Chemical Society, vol. 85, no. 22, pp. 3533-3539, Nov. 1963.

[31] R. G. Pearson, "Recent advances in the concept of hard and soft acids and bases,” Journal of Chemical Education, vol. 64, no. 7, pp. 561-567, Jul. 1987.

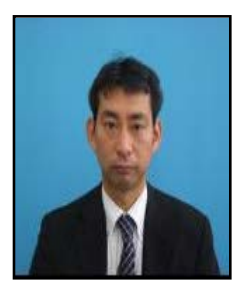

Takaaki Wajima was born in February 1976 in Saga Prefecture, Japan. He has been an associate professor in the Department of Urban Environment Systems, graduated from School of Engineering, Chiba University, Japan, since 2013. He received his bachelor's degree and master's degree in resource engineering from Kyoto University, Japan, in 1998 and 2000, respectively, and his $\mathrm{PhD}$ in environmental mineralogy and technology from Kyoto University, Japan, in 2004. His main $\mathrm{PhD}$ research theme was "Micro-porous materials synthesized from paper sludge ash at low temperature, and its chemical mineralogy." In 2004, he moved to the Institute of Ocean Energy at Saga University to work as a postdoctoral researcher, and from 2007 to 2013, he was an assistant professor at Akita University, Japan. His main research interests are waste recycling, resource recovery, and environmental purification. 